\title{
Music Education and Effective Teaching: Perspectives from a Critical Review
}

\author{
Eleonora Concina \\ University of Padova
}

\begin{abstract}
Effective teaching is an essential condition for fostering learning in instrumental and vocal music education. The role of the teacher in music lessons has to be considered in a multidimensional perspective, since it involves different personal and professional aspect in a one-to-one educational relationship. To improve teaching in the music field it is necessary to understand all these elements, the connections between them, and their impact on music teachers' training and professional development. The aim of the present paper is to consider some of these characteristics, and to discuss the relationships between them within music teacher's professional activity. Findings will provide the basis for planning future research studies, which may lead to define the main predictors of music effective teaching. Impact on music teachers' training is also considered, since it has proved to be a significant dimension of effective music teaching .
\end{abstract}

\section{Introduction}

Teaching-learning process involves different participants in an educational and institutional framework. In this condition, both teacher and students collaborate actively in order to reach shared educational aims. They are involve in a dialogical process, in which both protagonists work to develop a critical ability for understanding and facing all the aspects of the real world [1].

Focusing on teacher's action, "effective teaching" represents a way of managing this process with the aim not only of promoting the acquiring of contents and skills, but also of enhancing the building up of student's personality and independence [2]. This is based on the consideration that teachers' activity goes beyond the walls of the classroom and the pages of school text-books. Teaching effectiveness cannot be measured only with students' academic results; it affects the whole personal growth of students, promoting lifelong benefits, enhancing transferable skills and preparing the individuals for their future life [3]. Moreover, nowadays the role of the teachers includes also a broader social dimension, since they have to manage the relationships and the work with the students, the colleagues, the institutions, and the families [4]. Considering this, the impact of their professional activity has effects on the individuals, of course, but also on the whole society. For these reasons, it becomes essential to understand how to foster effectiveness in teaching.

The analysis of the elements characterizing effective teaching seems to be very complex because of the multidimensionality of the educational process. The teacher does not only have to know the content of the discipline, but she or he has also to be able to facilitate a global development of the students, promoting and sustaining specific abilities, motivation, selfregulation and self-esteem. Learning results derived from the particular combination of all this aspects, and there is not any pre-determined recipe that allows to reach a perfect teaching- learning condition.

\section{Characteristics of Music Education}

To analyze the relationships between the elements of effective teaching is important for fostering student's better academic results, and for supporting the individual growth and promoting a positive educational context for all the participants involved in it [5]. While there are some aspects of effective teaching that may be considered as general, and so can be applied for the teaching process in all the fields of knowledge, there are several features that seem to be relevant mainly for specific subjects [6].

This is the case of music education. For instrumental and vocal music teaching, this analysis has to consider the particular characteristics of the educational activity in this learning domain. Music education presents some specific features which make it different from other academic disciplines. In the music field, the teaching-learning process is affected by several 
elements, which refer both to the teacher's and to the student's cognitive, motivational and psychological characteristics. More specifically, music lessons are characterized by an one-to-one relationship between teacher and pupil, a particular condition in which students has to relate with the teacher without the support of the classmates. Another element is represented by the learning objectives that music education have to promote: at the same time, it has to be supported the achievement of theoretical concepts (music theory, ear training, rhythmic skills) and of practical abilities (instrumental and vocal technique) and the development of an aesthetic and critical thinking in the student. Furthermore, in music teaching and learning, the influence of teacher's beliefs in the didactic method used has to be considered: different opinions on the nature of music ability, on the role of the pupils in the music lessons and on the aims of advanced music education may determine the selection of particular teaching methods, strategies and didactic principles. Finally, also the role of student's psychological, emotional, and motivational factors affecting the learning activity and its results (e.g. the role of music performance anxiety in influencing musical performance) needs particular attention in the definition of educational effectiveness. On the contrary of school lessons (where children and teenagers have to study several subjects, which they may like or not), attending instrumental music lessons is usually a free choice of the students, as it can be considered one of the possible activities offered for non-institutional education. For this reason, student's motivation and feelings may impair or foster the learning process that takes place during music lessons.

\section{Effective Teaching in Music Education}

For the specific characteristics of instrumental music lessons, effective teaching has been widely explored in music education research. Many studies focus on effectiveness in music teaching [7]: they present a great variety of research objects and methodologies. Different aspects of the music lessons have been taken into account, with the aim to explore in depth the influence they may have on the educational relationship and the learning process. Considering its main aims, educational research in music teaching domain has taken up two different directions: on the one hand, several authors have focused on single teaching components, with the aim to define their most effective elements; on the other hand, other studies have tried to identify effective teaching models for instrumental and vocal music, combining the results from previous experimental studies and the empirical dimension of practical educational experiences [8] [9]. Several studies offer a detailed overview of specific aspects of music teaching; here, the analysis has been focused on the real context of a music lesson or on the attitudes, beliefs and behaviors reported by music teachers. According to Brand, music education research has mainly considered two set of variables, the first represented by music teacher's personal positive characteristics, the second centered on specific aspects of music lessons that can be managed by the teacher [10]. In this perspective, the most studied components of music teaching have been teachers' beliefs about effective aspects of their professional activity, teacher-student relationship, teachers' educational strategies, interpersonal verbal and non-verbal communication [11] [12] [13] [14] [15].

Research studies previously described focused on single elements of teaching; for this reason, some authors tried to outline general models of effective teaching in music education. One of this model has been proposed by Lehman, Sloboda and Woody [8]. Considering research findings, they have identified five main categories in instrumental and vocal music teaching: 1) teacher-students relationship, which, in an effective teaching condition, has to be characterized by respect and a positive communicative system for fostering positive learning results; 2) the development of student's self-regulatory skills with the aim of promoting autonomy in learning; 3) the verbal communication, which has to balance teacher's verbalization and student's active participation; 4) the instructional cycle, which, for being more effective, has to be structured into three phases (task presentation by the teacher, student's performance, assessment and feedback given by the teacher); 5) teacher's training, since effective teaching is not the results of a natural and innate "gift" but it derives from abilities and attitudes that can be developed with professional education. Another model of effective music teaching has been developed by Townsend, who divided all the elements characterizing effective teaching into two main categories: "artistry" and "attitude". The first category is related to the artistic dimension of teacher's characteristics, regarding both musical and teaching skills [9]. Music teachers have to be 
endowed with musical skills: they have to know how to play and what can be played by the pupils. At the same time, teachers need to develop particular didactic and educative abilities. The second category refers to the teacher's attitude toward the student. This dimension includes all the behavior that characterized teacher-student relationships; the use of an emphatic behavior and of an adequate communicative system, which could promote the success in music achievement. Townsend underlines that both these dimensions are involved in teaching effectiveness; to possess only the "artistic" component of teaching is not sufficient to sustain students' achievement and to reach specific learning goals. Most important, musical content and skills has to be presented with an effective communicative system.

With regard to music education research, findings have highlighted how different variables are involved in an effective teaching process: they suggest the importance of an interpersonal relationship based on empathy and acknowledgment of student's needs, where teacher and student share a communicative system which enables a mutual constructive exchange. Among this professional characteristics, teacher's beliefs and social abilities have a significant impact in enhancing students' learning and academic motivation [11] [16]. Professional training is recognized as the main activity for developing and enhancing teacher's skills directly involved in the educational relationship. Through it, it is also possible to investigate teacher students' beliefs about effective music teaching and to promote critical reflections on what are the main features of teaching effectiveness. All these aspects suggest that in building an effective teaching condition characteristics from personal, professional and contextual dimensions are strictly involved.

\section{Conclusions}

Research studies here considered have analyzed in depth the role of several specific components of teaching process in music; findings suggest that there are many dimensions connected to teacher's and student's activity and to the educational context that affect effective teaching in music. However, in most of the studies considered there are some critical points related to the methodology and the research objects that need to be discussed.

Many research projects have used case study methodology, presenting a detailed analysis but with no generalizable results. Case study methodology uses multiple sources of information in order to examine in detail a single event or object, this is very useful when a specific issue has to be analyzed in all his aspects, but, as a qualitative methodology, it does not allow to make generalizations from its findings [17].

Moreover, as previously reported, many models of effective music teaching have been presented, but they need further experimental validation. Indeed, they can take credit for having proposed a general and multidimensional structure of effective teaching in music, but they do not try to confirm these hypothetical schemes with experimental studies. Conversely, in several studies many elements have often been analyzed separately, without including a more wide view that can connect them into a general model of teaching. From all these perspectives it emerges the need of combining the findings derived from single studies with the proposals of a more complex structure of effective teaching concept.

Finally, at a more practical level, few studies have considered the role of specific training in fostering abilities that can have an impact on teaching. This point is very crucial, since it can be assumed that one of the main aims of educational research is to offer suggestions for improving the teaching-learning process.

To represent the complexity and multidimensionality of effective teaching in the musical field a more comprehensive view of effective music teaching is needed, in order to enhance teaching and learning processes. For better understanding the impact of different aspects on teaching effectiveness, a new approach has to be developed, in which previous research findings would be integrate with the proposals emerged in the field of practical music teaching. Expanding the knowledge about music effective teaching may be positive for both teachers, who can reflect on their educational activity and work to improve specific aspects of their professional competences, and for students, who can find the proper support and facilitation not only for their academic learning but also for their personal growth.

\section{Future Work Suggestions}

A research project has been developed from all these reflections. The suggestions that derived from this critical analysis sketch out a research line in the field of music education.

The main aim of this future study is to analyze and to propose a more complete overview of 
effective teaching in music. The research question is whether it is possible to identify specific psychological and professional characteristics of the instrumental and vocal music teacher which can influence several components of effective music teaching. A quantitative methodology will be used, in order to test the hypothesis; the collection of data will be made with a battery of questionnaires proposed to music teachers of Conservatories, music schools, and high schools. Participants will be instrumental and vocal music in-service teachers, with some years of experience in teaching music to young learners. The questionnaires proposed regard some particular professional and personal areas: teacher-student relationship, teaching method, self-efficacy, social skills, beliefs on musical ability. The main predictors of some teaching components will be identified, to integrate the results with previous research findings in a general model of instrumental and vocal music teaching.

Expected findings will provide some educational implications, since they would become the starting point to hypothesize and design professional trainings for instrumental and vocal music pre- and in-service teachers. Personal characteristics that will emerge as predictors of specific teaching components may become the subjects of training courses in order to enhance music teachers' professional competences.

\section{References}

[1] Freire, P. (1970) Pedagogia do oprimido, Tierra Nueva, Montevideo (Engl. ed. Pedagogy of the oppressed, Herder and Herder, New York, 1970)

[2] Rogers, C. (1969) Freedom to Learn. Charles E. Merrill Publishing Company, Columbus, Ohio.

[3] Stronge, J. H. (2007) Qualities of effective teachers, Association for Supervision and Curriculum Development, Alexandria, VA.

[4] Campbell, J., Kyriakides, L., Muijs, D., and Robinson, D. (2004) Assessing teacher effectiveness. Developing a differentiated model. Routledge Falmer, London.

[5] Kai-Wen Cheng, E., and Durrant, C. (2007) 'An investigation into effective string teaching in a variety of learning contexts: a single case study', British Journal of Music Education, 24 (2), pp. 191-205.

[6] Departement for Education and Employment UK Govern-DfEE (2000). Research into teacher effectiveness: a model of teacher effectiveness. Report by Hay-MacBer for the DfEE. London: DfEE

[7] Duke, R. A., 'Measure of instructional effectiveness in music research', Bulletin of the Concil for Research in Music Education, 1999/2000, 143, pp. 1-48

[8] Lehmann, A. C., Sloboda, J. A., Woody, R. H. (2007) Psychology for Musicians. Understanding and Acquiring the Skills. Oxford University Press, Oxford.

[9] Townsend, A. S. (2011) Introduction to Effective Music Teaching. Artistry and Attitude. Rowman \& Littlefield Publishers, Plymouth, 2011.

[10] Brand, M., (2009) 'Music teacher effectiveness: selected historical and contemporary research approaches', Australian Journal of Music Education, 2009, 1, pp. 13-18.

[11] Bautista, A., Pérez Echeverría, M. Del P, and Pozo, J. I. (2010) 'Music performance teachers' conceptions about learning and instruction: a descriptive study of Spanish piano teachers', Psychology of Music, 38 (1), pp. 85-106.

[12] Creech, A., and Hallam., S. (2010) 'Interpersonal interaction within the violin teaching studio: the influence of interpersonal dynamics on outcomes for teachers', Psychology of Music, 2010, 38 (4), pp. 403421.

[13] Zhukov, K. (2013) 'Interpersonal interactions in instrumental lessons: teacher/student verbal and nonverbal behaviours', Psychology of Music,, 41 (4), pp. 466-483.

[14] Young, V., Burwell, K., and Pickup, D. (2003) 'Areas of study and teaching strategies instrumental teaching: a case study research project', Music Education Research, 5 (2), pp. 139-155.

[15] Karlsson, J., and Juslin, P. N. (2008) 'Musical expression: an observational study of instrumental teaching', Psychology of Music, 36 (3), pp. 309-334.

[16] Juchniewicz, J. (2010) 'The influence of social intelligence on effective music teaching', Journal of Research in Music Education, 58 (3), pp. 276-293

[17] Creswell, J. W. (2012) Qualitative inquiry \& research design,. Choosing among five approaches, Third Edition, SAGE Publications, Thousand Oaks, CA 